\title{
AC 2009-634: THE USE OF MATHEMATICAL THINKING TO DEAL WITH UNCERTAINTY IN A CAPSTONE DESIGN COURSE
}

Ming-Chien Hsu, Purdue University

Monica Cardella, Purdue University 


\title{
The Use of Mathematical Thinking to Deal with Uncertainty in a Capstone Design Course
} mathematics, engineering design, uncertainty, situated cognition, naturalistic inquiry

\begin{abstract}
In order to understand how engineering students deal with uncertainty in a normal design task, we studied a team of five industrial engineering students in a capstone class over the course of five months as they worked with professional engineers from a local company. The framework of mathematical thinking that guided this study as we investigated how these students engaged in mathematical thinking while they designed. We found that two aspects of mathematical thinking were most often used when the students were dealing with uncertainty in their design: problem solving strategies and the use of social resources. These findings have the potential to influence how engineering educators integrate engineering science and real-world design tasks.
\end{abstract}

\section{Introduction}

There have been debates among the engineering education community on how and how much mathematics should be taught to engineering students. The debates arise because studies like the one done by Underwood show that mathematics used in people's jobs are different from what is taught in school ${ }^{1}$. Also, studies such as the one by Jonassen et al. show that engineering workplace problems are ill-structured ${ }^{2}$. So the question of how teaching well-structured problems in engineering science courses would transfer to ill-structured design tasks is another motivation for rethinking the engineering curriculum. Dym pointed out that design problems have the quality of "divergent inquiry", that "there exist multiple alternative known answers, regardless of being true or false, as well as multiple unknown possible answers for any given question" 3 . That quality seems to conflict with the principles and values of "convergent thinking" that are at the core of engineering science approaches, which always lead to a specific set of answers.

Design is a complex cognitive process, and a good designer has to tolerate ambiguity and handle uncertainty ${ }^{3}$ that can occur or reemerge at any stage of design. This paper will address the question of how engineering students deal with the ambiguity and uncertainty that emerges throughout the process of design (in this paper, we will only use the term "uncertainty"). The uncertainty students might encounter in design could be in a number of forms: information that needs to be gathered, precise information that does not exist, and multiple alternatives that students must chose between. Individuals may take multiple approaches to deal with the 
uncertainty and we would like to investigate how engineering students respond to the uncertainty.

We used a framework of mathematical thinking to examine how engineering students deal with uncertainty in design. Currently, in many engineering curricula, the first three years consist of mathematics and science courses. In the fourth year, a capstone design project is added to provide a chance for students to deal with complex real-world problems. Determining how students use mathematical thinking in this capstone design project will potentially inform engineering educators on integrating engineering science and practical design tasks.

\section{Theoretical framework}

In order to investigate how engineering students learn and use mathematics, a broad notion of mathematical thinking has been adopted for this study. Rooted in Alan Schoenfeld's description of five aspects of mathematical thinking ${ }^{4}$, this study not only examines the mathematical content knowledge students use, but also problem solving strategies, effective use of one's resources, mathematical beliefs and affects, and mathematical practices.

Shoenfeld's discussion is mostly based on a cognitive perspective. When referring to the use of resources, Schoenfeld meant the metacognitive processes, such as planning and monitoring. However, in order to understand how engineers use mathematics, we must also consider the problem from a situated perspective in the collaborative context of teammates, teachers, etc. To understand problem solving, some researchers within the mathematics education community have advocated for combining cognitive and situative approaches to account for the social and material context a problem solver acts in. Greeno and his colleagues suggest that this is particularly appropriate when considering groups of people or "intact activity systems", while the cognitive perspective focuses on individuals ${ }^{5}$. We thus integrate social resources and material resources into the framework, as influenced by McGinn and Boote's discussion on

their study of mathematical thinking ${ }^{6}$. The five aspects of mathematical thinking investigated in this study are presented in Table 1.

For this study, we examine how designers engage in mathematical thinking while designing. Therefore, besides the mathematical thinking framework, we use the model of engineering design created by Atman et al. ${ }^{7}$ (See Table 2). This particular model was built on content analysis of seven engineering text books and has been used in several studies to examine the design behaviors of engineering students and engineering practitioners ${ }^{7,8}$. 
Table 1: Aspects of Mathematical Thinking

\begin{tabular}{ll}
\hline Aspect & Definition/Description \\
\hline Knowledge Base & Cognitive Resources: Mathematical Content Knowledge \\
Problem Solving Strategies & Global or local strategies learned from mathematics courses \\
Use of Resources & Social Resource: Peers, Experts \\
& Material Resources: textbooks, time, computers \\
& Use of Resources: metacognitive processes such as planning and monitoring \\
Beliefs and Affects & Beliefs about mathematics and one's mathematical ability, Feelings towards \\
& mathematics, Emotions or feelings experienced \\
Mathematical Practices & Activities or actions that engineers or mathematicians engage in, or activities that \\
& involve mathematics. \\
\hline
\end{tabular}

Table 2: Design activities (from Atman et al.6)

\begin{tabular}{ll}
\hline Design Activity & Description \\
\hline Problem Definition & $\begin{array}{l}\text { Define what the problem is by identifying constraints, criteria, reading and } \\
\text { questioning problem statement }\end{array}$ \\
Gather Information & $\begin{array}{l}\text { Search for and collect data } \\
\text { Gevelop possible ideas for a solution, brainstorm, list different alternatives }\end{array}$ \\
Menerate Ideas & Describe how to build an idea, measurement, dimensions, calculations \\
Feasibility Analysis & Determine workability, does it meet constraints, criteria, etc. \\
Evaluation & Compare alternatives, judge opinions \\
Decision & Select one idea or solution among alternatives \\
Communication & Communicate the design to others \\
\hline
\end{tabular}

\section{Data collection and analysis}

In order to understand how engineering students deal with uncertainty in a normal design task, a team of five industrial engineering students was studied while they worked on a project for their capstone design course as informed by the situated framework. The specific methods we used were observations and semi-structured interviews ${ }^{9}$.

The students interviewed were asked questions on what they had learned from their mathematics courses, and how they used what they had learned from their mathematics courses in the capstone design. Their responses covered all five aspects of mathematical thinking in Table 1. Any activity mentioned by students as previously learned in mathematics courses was counted as mathematical thinking. These interview responses were served as the main filter for analysis of the observation data ${ }^{9}$.

In addition, observation notes were collected during 22 of the design team's meetings over the course of 5 months. The project was to design a new satellite delivery center for a package delivery service on a populated island off the mainland, where the main package-sorting hub was located. The plan was that in the morning one or two trucks from the mainland would go on the ferry to go to "Bellissima Island" (both the location and the student names are pseudonyms). The goods were to be sorted at the satellite center and to be delivered on the 
island. At the end of the day the express packages were to be delivered back to mainland, so that they could be sorted and then taken to the nearby airport. The problem is multilayered as seen in Figure 1.

Figure 1: The investigated multi-layered design problem

\begin{tabular}{|c|c|c|c|}
\hline & cost & & \\
\hline & & location & \\
\hline & & & bathrooms \\
\hline & Puilding & type of building & storage \\
\hline & & & wash trucks \\
\hline & & buy vs. lease & \\
\hline & & commute? & \\
\hline $\begin{array}{l}\text { Main problem: } \\
\text { Should we build a satellite center? }\end{array}$ & drivers & how many? & \\
\hline & & part time vs. full time & \\
\hline & enting & statistical model? & \\
\hline & Dotitis & ARENA simulation & \\
\hline & & keep it under union regulation & \\
\hline & schedule & enough time to sort & \\
\hline & & moating dudlino & on island \\
\hline & & & back at mainland \\
\hline
\end{tabular}

The meetings were audio-recorded and transcribed. The transcripts were segmented into units ranging from a partial sentence to two sentences in length. Then the transcripts were analyzed by three coders using a constant comparison methodology; they were coded inductively, and each segment of data was compared with one or more categories to determine its relevance and with other segments of data similarly categorized. ${ }^{10}$. In cases where it was determined that the data segment did not fit in an existing category (i.e. the coders compared it to segments in all existing categories and the new segment was not consistent with any of the existing categories), a new category was formed. Two coding schemes were used in the analysis. The first one was the mathematical thinking activities that emerged from the data, and the second was the design activities shown in Table 2, defined by Atman et al. ${ }^{7}$. While this paper focuses on how the students deal with uncertainty, the other themes are discussed in greater detail elsewhere ${ }^{11}$.

In this paper, we present findings from an analysis of a subset of the data: transcripts from design meeting $1,2,4,7,12,13$, and 14 , out of 22 meetings.

\section{Findings and discussion}

Our analysis of the coding shows that when dealing with uncertainty, these students most often engaged in two aspects of mathematical thinking: mathematical problem solving strategies and 
using social resources. The specific problem solving strategies most often employed were: i) separating a problem into smaller problems, ii) forming problems, and iii) guessing and verifying (See Table 3). These were the strategies that the students interviewed reported learning in mathematical courses. As for the uses of social resources, industry partners from the client company were whom the students sought help from to i) gather mathematical content knowledge and information, and ii) check the feasibility of their ideas. These two design activities, gathering information and checking feasibility, were ones the students employed most frequently to deal with uncertainty (See Table 4).

Table 3: The design team's uses of each aspect of mathematical thinking to deal with uncertainty

\begin{tabular}{|c|c|c|}
\hline $\begin{array}{l}\text { Aspect of mathematical } \\
\text { thinking }\end{array}$ & $\begin{array}{l}\text { \# of times used to deal } \\
\text { with uncertainty in the } \\
\text { investigated meetings }\end{array}$ & $\%$ \\
\hline Knowledge Base & 7 & 4.7 \\
\hline Problem Solving Strategies & 56 & 37.8 \\
\hline $\begin{array}{l}\text { Use of } \\
\text { Resources: }\end{array}$ & 38 & 25.7 \\
\hline ii. cognitive & 30 & 20.3 \\
\hline iii. material & 12 & 8.1 \\
\hline Beliefs and Affects & 1 & 0.7 \\
\hline Mathematical Practices & 4 & 2.7 \\
\hline Total & 148 & 100.0 \\
\hline
\end{tabular}

Table 4: The number of occurrences design activities during which industrial partners were used as resources to deal with uncertainty

\begin{tabular}{|c|c|c|}
\hline Design activities & \# of occurrences & $\%$ \\
\hline Problem Definition & 34 & 13.1 \\
\hline Gather Information & 94 & 36.4 \\
\hline Generate Ideas & 16 & 6.2 \\
\hline Modeling & 31 & 12.0 \\
\hline Feasibility Analysis & 51 & 19.8 \\
\hline Evaluation & 7 & 2.8 \\
\hline Decision & 1 & 0.4 \\
\hline Communication & 24 & 9.3 \\
\hline Total: & 258 & 100.0 \\
\hline
\end{tabular}

\section{Mathematical Problem Solving Strategies}

Separate a problem into smaller problems. The problem solving strategies that the students most often employed when they came across uncertainty in design was to separate a problem into smaller problems. This made the problem more manageable by attending to one particular aspect of the problem at a time, rather than the problem as a whole.

Consider an excerpt taken from the team's $7^{\text {th }}$ design meeting, when the students were deliberating the location of the satellite center. A student recognized that one of the most 
important aspects they should be considering was whether it was indoor or outdoor. The student further gave reasoning as to why they should be thinking about this aspect of the problem, and it led to further discussion of the population growth in that area.

"One of the main things we're looking at as far as location is whether or not they're looking for an indoor or outdoor facility. We're thinking outdoor facility might not be as good for year round operation, or if you're planning to expand, grow, expand, since this is an area where the population keeps growing, so..."

Thus, instead of considering the problem as a whole, they broke the problem down into smaller pieces and focused on a smaller problem that they thought crucial.

The next excerpt is another example of how student designers separate a problem into smaller problems. In the beginning of the $1^{\text {st }}$ meeting, they started discussing the problem of keeping the truck drivers' working hours under union's regulation of eight hours. Then, a student mentioned the issue of whether they needed to pay the drivers to commute from other parts of the city, which is a smaller part of the larger problem of finding drivers. The discussion followed targeted on this smaller problem.

"One thing right now they have to go all the way to Bellissima Island. You're talking about 6 package cars. We don't even know if we have to pay them to commute..... already get paid 9 hours a day, overtime, cut it down to an 8 hour day."

There were many other cases where the students also separated a problem into smaller problems as a strategy for dealing with uncertainty in their task. When uncertainty arose, the students changed their focus to the most important facet of the problem they recognized, the specific constraints they were facing, or other aspects worth considering.

Transform the problem. The next most frequently employed mathematical problem solving strategy is transforming the problem. This strategy is used when a problem is unfamiliar or complex. Designers may transform the problem by simplifying or decomposing the problem so it resembles one that individuals are more familiar with. In the analyzed design process, students used this particular strategy to transform more complex situations, theories, or tasks into something simpler when uncertainty was raised. In doing so, all the team members were able to understand the discussion and to proceed further in design.

For example, in the following excerpt, Fil expressed confusion about the relationship between criteria and goals when they talked about design reports. So, Diego described that in simpler terms to show how criteria and goals were connected in engineering design.

Fil: I didn't realize this was criteria performance goals, I thought there were separate...

Diego: The thing about our goals is, when you try to figure out what the best thing is, you 
have to have criteria for determining how you're going to meet your goals so that all you have to put in that section.

In the next example, Diego suggested using queuing theory in the analysis, which confused his teammate Fil. Thus, he transformed queuing theory using situations they might come across in the design, which made the concept understandable to his teammates.

Fil: I don't know how to use queuing theory.

Ben: Nobody around here does either.

Diego: People have to wait, the queues that the drivers have to wait for, wait to there's queue time getting off the ferry.

Fil: Oh, I see...oh physically sorting the package too. If we sort them before we sort them off, we can reduce the time that it takes for the package car.

After lengthy discussion on what data to be compiled in the computer simulation in the $4^{\text {th }}$ design meeting, the team seemed to be out of focus, as Diego's expression pointed out: "The doc was saying you got too much data already. We don't know what you do with it, you know". Fil transformed this complex situation into a manageable one by trying to keep things in check, using specific terms to communicate. His comments directed the discussion back to track.

Fil: So what you want to know is like, how much volume, right? Volume per day? Cause that's what I was thinking, but I don't know if....

Diego: I'm more interested in... cost per day, to run all the loops.

Fil: Cost per day? All the loops? So we'd need to know all the drivers... we're bringing. So how would we do that?

The students used the strategy of transforming the problem to interpret and reinterpret the problem so that a more complex situation could be understood by other members of the team.

Guess and verify. During mathematical problem solving, students sometimes take a guess at how to proceed with a mathematical proof. In the course of following that approach, they will determine whether or not the approach is effective. This strategy allows individuals to proceed with task when uncertain about which path to take. Individuals might also guess other uncertain information in order to be able to progress and later verify the accuracy of the guess. Our analysis shows that the strategy of guessing and verifying was often used in the examined design task. When the design team did not know what approach to use or how big one quantity should be, they guessed. Those guesses were usually verified by others in the team immediately after, or the guesses gave them something to work on first and to be verified later.

For instance, in the design meeting in which the team met up with two industrial partners, the problem of unloading the truck from mainland and loading the trucks for delivery came up. The 
team had to simulate the loading/sorting/loading process with computers, but they were not sure how fast the unload device could work. In the following excerpt, they were discussing the realistic number that the machine could unload in an hour. There were exchanges between students (Diego and John) and industrial partners (P1 and P2). The students guessed the number they could use, and the numbered were either verified or rejected by the industrial partners:

Diego: .... and so we took these numbers and took 285 for the stop

Partner2: Probably the way you've got this set up right here, develop the car. Realistically you're probably going to be a little closer to... these numbers right down here

Diego: Okay. Which actually is fine, because....

Partner2: 160, 176, I was going to say 159 . So, I would probably take, these two numbers down here, wouldn't go any higher than 176 realistically.

Diego: Oh, so take the bottom three here.

Partner2: Yeah, I would take the bottom three......

While not unique to mathematical thinking, the problem solving strategies were what these students identified as what they have learned in mathematics courses. Frequent usage of these strategies suggests that mathematics courses are important for engineering students, because they can learn thinking processes and strategies.

\section{Use of Social Resources}

Another category of mathematical thinking that these students most often employed was the use of resources; particularly, in the form of people. The team's greatest social (people) resource was the industrial partners from the company sponsoring the capstone project. These industrial partners provided expert knowledge in different domains of the inner workings of that company. Therefore, it is not surprising that the analysis shows that when the engineering students encountered uncertainty, they most frequently gathered information about the project from the industrial partners and checked feasibility of their design with the industrial partners.

More specifically, at some incidences of uncertainty, these students asked the industrial partners for more information or expressed how to go about gathering more information from the industrial partners. In turn, the industrial partners shared what they knew with the students, and they kept the team in focus by pointing out aspects the team might have missed. For example, in the $7^{\text {th }}$ meeting, the students had a problem of determining the process for sorting the packages. They presented the three options considered in front of an industrial partner in hope of some suggestions from him. The industrial partner pointed out that the important factor to be considered was the cost associated with the volume of packages going to the island. $\mathrm{He}$ 
told the students:

Look at average March or look at average September because our volume trend is kind of like a dual peak over our entire annual cycle..... So as far as looking at volume forecasting or volume models we always use March or September. If you plan your resources, your facilities, your equipment, your trailers, your package cars to meet the needs of those two months or the volume of those two months, then you can easily get through the rest of the months.

Although the students had the data at hand, they had not realized how the data could be utilized. The industrial partner gave student valuable suggestions as the "insider" to the company's operation, so students could overcome uncertainty and proceed with designing.

In addition, when facing uncertainty in design, the students sometimes asked the industrial partners how feasible their solution elements were. The industrial partners commented on the feasibility of ideas, workability of a solution element, ways to make a proposed solution more feasible, or alternative solutions. For instance, in the $13^{\text {th }}$ meeting, the students were dealing with the problem of loading/unloading devices at the satellite delivery center. The discussion was loaded with mathematical modeling. The students often checked the feasibility of their ideas and guesses with the industrial partners present, like the following exchanges between the students and one industrial partner as they talked about estimating the volume of packages:

Partner1 : What'd you use for the unload out of the main vehicle onto the belt? The main car that comes from the Seattle building over to the Island

Diego: 950 to 1100 is what, is he told me, so I just averaged that, that's 1025 .

Partner1: 1025, that's with a really good unload device, good rollers. That's pretty aggressive. I mean, 12 rollers.

Diego : Oh really?

The industrial partner had knowledge of the inner working of the company, and thus they could construct reasoning based on "common senses". They were valuable resources for the students to check if their design is feasible, reasonable, and at the same time fitting the criteria and limitations. Also, they were beneficial resources as the students were learning ways to gather information, such as formulating good questions to ask the industry partners.

\section{Implications}

Uncertainty in design can be challenging and even overwhelming at times for students. We can see that these engineering students relied on social resources as well as the problem solving strategies identified as learned in mathematics courses to deal with uncertainty arose in the process of engineering design. The way these students cope with uncertainty in an ill-structured problem could provide us with some suggestions on how to integrate practical 
engineering tasks and engineering sciences; particularly, how mathematics should be taught to engineering students to help them in the process of design. Besides the content knowledge aspect of mathematics, engineering educators should consider other aspects of mathematical thinking, including the problem solving strategies that engineering students could learn in mathematics courses as well as the social resources available to them. As stated earlier in the paper, the problem solving strategies and social resources are not unique to mathematics courses or mathematical thinking; they were nevertheless part of what the interviewees reported learning in mathematics courses. Therefore, this is one specific area that educators might consider. Finally, reminding students the relation between problem solving and design could potentially help them transfer what they have learned in engineering sciences courses to design.

\section{Acknowledgements}

This work was supported by the Center for Engineering Learning and Teaching at the University of Washington and the LIFE (Learning in Informal and Formal Environments) Center, which is funded by NSF grant SBE-0354453. Any opinions, findings and conclusions or recommendations expressed in this material are thoseof the author(s) and do not necessarily reflect the views of the National Science Foundation. We would also like to thank Tracie Rickert and Aki Sakamoto for their assistance with the coding of the data. We would like to thank the engineering educator who partnered with us by allowing us to interview his students, and we would especially like to thank all of the engineering students who participated in the study.

\section{Bibliography}

1. Underwood, D., Is Mathematics Necessary. The College Mathematics Journal 1997, 28, (5), 360-364.

2. Jonassen, D.; Strobel, J.; Lee, C. B., Everyday Problem Solving in Engineering: Lessons for Engineering Educators. Journal of engineering education 2006, 95, (2), 139.

3. Dym, C. L.; Agogino, A.; Eris, O.; Frey, D. D.; Leifer, L., Engineering Design Thinking, Teaching, and Learning. Journal of Engineering Education 2005, 94, (1).

4. Schoenfeld, A. H., Mathematical thinking and problem solving. Erlbaum: Hillsdale, NJ, 1994.

5. Greeno, J. G., The Situativity of Knowing, Learning, and Research. American Psychologist 1998, 53, (1), $5-26$.

6. McGinn, M. K.; Boote, D. M., A First-Person Perspective on Problem Solving in a History of Mathematics Course. Mathematical Thinking and Learning 2003, 5, (1), 71-107. 
7. Atman, C.; Chimka, J.; Bursic, K.; Nachtmann, H., A comparison of freshman and senior engineering design processes. Design Studies 1999, 20, (2), 131-152.

8. Atman, C. J.; Cardella, M. E.; Turns, J.; Adams, R., A Comparison of Freshman and Senior Engineering Design Processes: An In Despth Follow-Up Study. Design Studies 2005, 26, (4), 325-357.

9. Cardella, M. E., Which mathematics should we teach engineering students? An empirically grounded case for a broad notion of mathematical thinking. Teaching Mathematics and its Applications 2008, 27, (3), 150-159.

10. Strauss, A. L.; Corbin, J. M., Basics of qualitative research. Thousand Oaks, CA: Sage Publications 1990.

11. Cardella, M. E. Engineering Mathematics: an Investigation of Students' Mathematical Thinking from a Cognitive Engineering Approach. University of Washington, Seattle, 2006. 